\title{
Column-Based Technology for CD9-HPLC Immunoaffinity Isolation of Serum Extracellular Vesicles
}

Jianhui Zhu ${ }^{1 *}$, Jie Zhang ${ }^{1}$, Xiaohui Ji ${ }^{1,2}$, Zhijing Tan ${ }^{1}$, David M. Lubman ${ }^{1 *}$

${ }^{1}$ Department of Surgery, University of Michigan Medical Center, Ann Arbor, MI 48109, USA

${ }^{2}$ Chongqing Key Laboratory of Translational Research for Cancer Metastasis and Individualized Treatment, Chongqing University Cancer Hospital, Chongqing 400030, China

\section{Supporting Information}

\section{Table of Contents}

Figure S1. HPLC chromatograms of (A) $10 \mu \mathrm{L}$ human serum on the CD9-IAC column and (B) $40 \mu \mathrm{L}$ human serum on an underivatized column which was packed with the hydrazide resin without antibody.

Figure S2. Representative chromatogram of blank between sample injections on the CD9-IAC column shows no carryover between runs.

Figure S3. Scatter plot of the EV peak area for the 50 replicates of $40 \mu \mathrm{L}$ of serum enriched from the CD9-IAC column. The CV for the 50 replicates was $9.7 \%$.

Figure S4. SDS-PAGE analysis of the EV fraction eluted from the CD9-IAC column with a comparison of the post-column cleaning step using a $50 \mathrm{kD}$ MWCO centrifugal filter.

Figure S5. An image of the entire membrane of Western blotting analysis of CD9 in the EVs.

Table S1. List of 482 proteins identified in EVs isolated from $40 \mu \mathrm{L}$ of serum (n=3) and the percentage contents of the top 10 serum proteins and apolipoproteins in the three replicates, respectively 

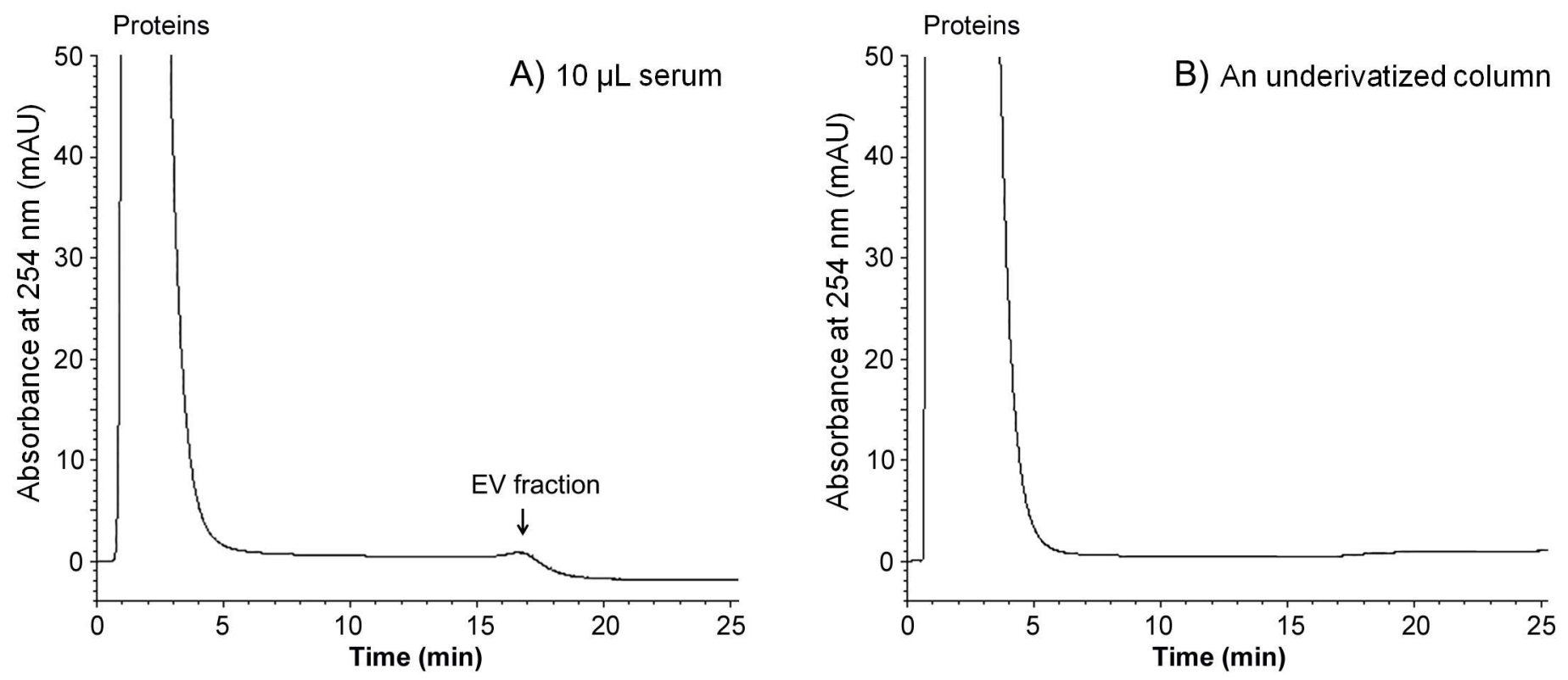

Figure S1. HPLC chromatograms of (A) $10 \mu \mathrm{L}$ human serum on the CD9-IAC column and (B) $40 \mu \mathrm{L}$ human serum on an underivatized column which was packed with the hydrazide resin without antibody. 


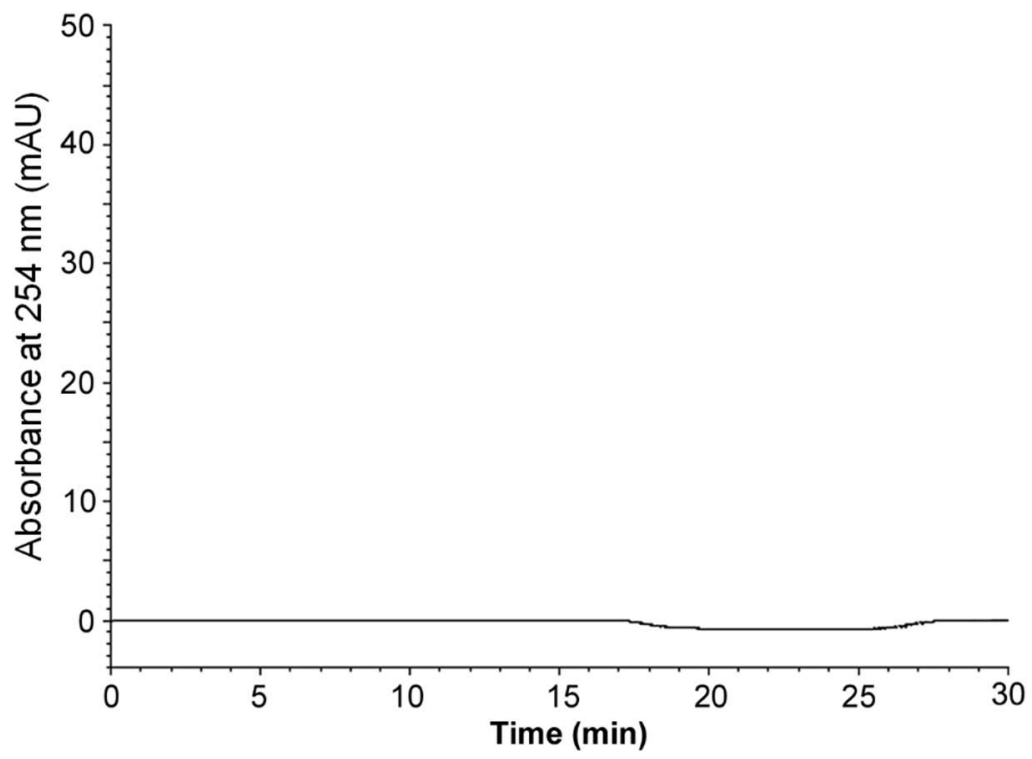

Figure S2. Representative chromatogram of blank between sample injections on the CD9-IAC column shows no carryover between runs. 


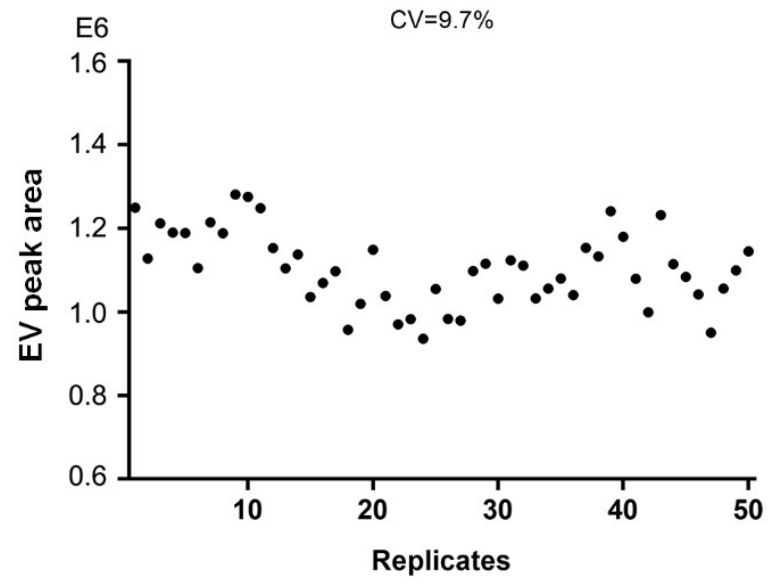

Figure S3. Scatter plot of the EV peak area for the 50 replicates of $40 \mu \mathrm{L}$ of serum enriched from the CD9-IAC column. The CV for the 50 replicates was $9.7 \%$. 


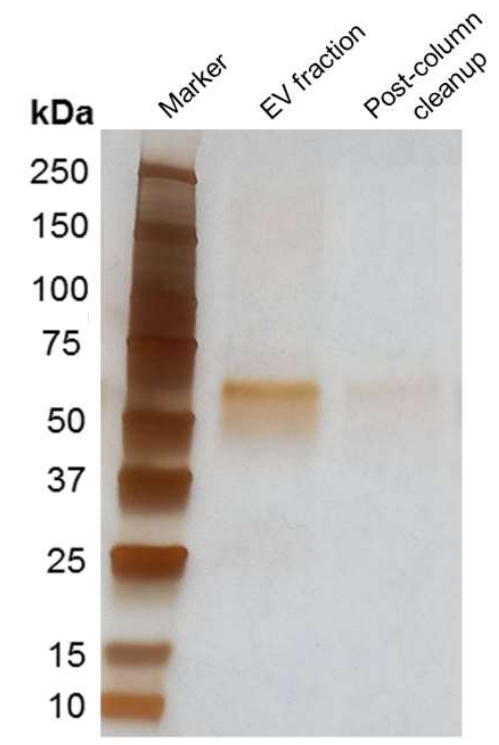

Figure S4. SDS-PAGE analysis of the EV fraction eluted from the CD9-IAC column with a comparison of the post-column cleaning step using a $50 \mathrm{kD}$ MWCO centrifugal filter. Samples were subjected to 4-20\% SDSPAGE without lysis and visualized by silver staining. ImageJ was employed to quantify protein bands on the gel with a total amount of $4.5 \mu \mathrm{g}$ of a protein ladder as a reference. The co-eluting serum proteins in the EV fraction was estimated as $\sim 0.55 \mu \mathrm{g}$ before the post-column cleaning and $\sim 0.11 \mu \mathrm{g}$ after the post-column cleaning. The result showed that the co-eluting serum proteins were reduced by $80 \%$ after the post-column cleanup using the $50 \mathrm{kD}$ MWCO filter. 


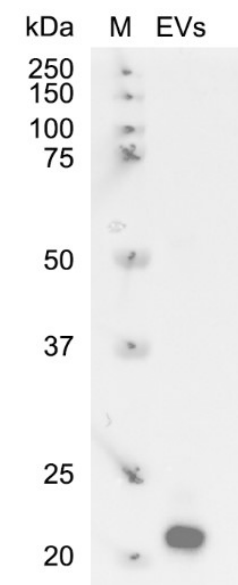

Figure S5. An image of the entire membrane of Western blotting analysis of CD9 in the EVs. 